\section{(1)}

CrossMark

\title{
GINA 2019: a fundamental change in asthma management
}

Treatment of asthma with short-acting bronchodilators alone is no longer recommended for adults and adolescents

Helen K. Reddel (10), J. Mark FitzGerald ${ }^{2}$, Eric D. Bateman ${ }^{3}$, Leonard B. Bacharier ${ }^{4}$, Allan Becker ${ }^{5}$, Guy Brusselle ${ }^{6}$, Roland Buhl 7 , Alvaro A. Cruz ${ }^{8}$, Louise Fleming $\mathbb{1 0}^{9}$, Hiromasa Inoue ${ }^{10}$, Fanny Wai-san Ko ${ }^{11}$, Jerry A. Krishnan ${ }^{12}$, Mark L. Levy (13 ${ }^{13}$, Jiangtao Lin ${ }^{14}$, Søren E. Pedersen ${ }^{15}$, Aziz Sheikh ${ }^{16}$, Arzu Yorgancioglu ${ }^{17}$ and Louis-Philippe Boulet ${ }^{18}$

Affiliations: ${ }^{1}$ Woolcock Institute of Medical Research, University of Sydney, Sydney, Australia. ${ }^{2}$ Respiratory Division, Faculty of Medicine, University of British Columbia, Vancouver, BC, Canada. ${ }^{3}$ Division of Pulmonology and Dept of Medicine, University of Cape Town and University of Cape Town Lung Institute, Cape Town, South Africa. ${ }^{4}$ Washington University and St Louis Children's Hospital, St Louis, MO, USA. 5 Section of Allergy and Clinical Immunology, Children's Hospital Research Institute of Manitoba, University of Manitoba, Winnipeg, MB, Canada. ${ }^{6}$ Dept of Respiratory Medicine, Ghent University Hospital, Ghent, Belgium. ${ }^{7}$ Pulmonary Dept, Mainz University Hospital, Mainz, Germany. ${ }^{8}$ ProAR Foundation and Federal University of Bahia, Salvador, Brazil. ${ }^{9}$ Respiratory Paediatrics, Imperial College, London, UK. ${ }^{10}$ Dept of Pulmonary Medicine, Graduate School of Medical and Dental Sciences, Kagoshima University, Kagoshima, Japan. ${ }^{11}$ Dept of Medicine and Therapeutics, The Chinese University of Hong Kong, Hong Kong. ${ }^{12}$ Breathe Chicago Center, University of Illinois at Chicago, Chicago, IL, USA. ${ }^{13}$ Sessional GP and Clinical Lead National Review of Asthma Deaths, UK. ${ }^{14}$ China-Japan Friendship Hospital, Peking University, Beijing, China. ${ }^{15}$ University of Southern Denmark and Kolding Hospital, Kolding, Denmark. ${ }^{16}$ Asthma UK Centre for Applied Research, The Usher Institute, The University of Edinburgh, Edinburgh, UK. ${ }^{17}$ Celal Bayar University, Medical Faculty, Dept of Pulmonology, Manisa, Turkey. ${ }^{18}$ Québec Heart and Lung Institute, Laval University, Québec City, QC, Canada.

Correspondence: Helen K. Reddel, Woolcock Institute of Medical Research, The University of Sydney, NSW, Australia. E-mail: helen.reddeldsydney.edu.au

@ERSpublications

GINA no longer recommends treating adults/adolescents with asthma with short-acting bronchodilators alone. Instead, they should receive symptom-driven (in mild asthma) or a daily corticosteroid-containing inhaler, to reduce risk of severe exacerbations. http://bit.ly/310LLzE

Cite this article as: Reddel HK, FitzGerald JM, Bateman ED, et al. GINA 2019: a fundamental change in asthma management. Eur Respir J 2019; 53: 1901046 [https://doi.org/10.1183/13993003.01046-2019].

In April 2019, the Global Initiative for Asthma (GINA) (box 1) published new recommendations that might be considered the most fundamental change in asthma management in 30 years. The new recommendations follow a decade-long programme of work by GINA, prompted by concerns about the risks and consequences of the long-standing approach of commencing asthma treatment with short-acting $\beta_{2}$-agonists (SABA) alone. These initiatives were aimed at obtaining evidence about effective treatment options for mild asthma and providing consistent messaging for patients and clinicians across the spectrum of asthma severity. 
For safety, GINA no longer recommends treatment of asthma in adolescents and adults with SABA alone. Instead, to reduce their risk of serious exacerbations, all adults and adolescents with asthma should receive either symptom-driven (in mild asthma) or daily inhaled corticosteroid (ICS)-containing treatment.

Here, we provide the background to these recommendations, summarise the evidence and rationale for the changes, and identify research gaps.

The risks of SABA were the focus of extensive research in the 1980s and 1990s following two international epidemics of asthma deaths [1], with case-control studies showing that over-use of SABA was associated with increased risk of asthma-related death $[2,3]$. Randomised controlled trials found no advantage in regular versus as-needed SABA [4,5] and, by the late 1990s, most guidelines recommended as-needed rather than regular SABA. In parallel, extensive evidence emerged of the protective value of regular ICS, with a dramatic reduction in the risk of asthma-related hospitalisations and death $[6,7]$. Large randomised controlled trials demonstrated that in mild asthma, low dose ICS reduced severe exacerbations by $\sim 50 \%$, in addition to controlling symptoms and improving quality of life $[8,9]$. However, acceptance of daily ICS was slow, partly based on physician concern about the serious side-effects seen with oral corticosteroids [1]. Concern about $\beta_{2}$-agonist risk in asthma largely shifted to long-acting $\beta_{2}$-agonists (LABA), with recommendations against LABA-only treatment, but in guidelines, SABA-only treatment remained unchallenged as the initial therapy for mild asthma, with ICS use recommended only for patients with frequent symptoms.

In 2007, GINA began actively searching for and reviewing evidence about treatment options for mild asthma, with a focus on reducing the risk of asthma-related exacerbations and death compared with SABA-only treatment. Multiple studies had demonstrated adverse effects of even short-term regular use of SABA alone, including reduced bronchoprotection and bronchodilator response, increased airway hyperresponsiveness, exercise-induced bronchoconstriction and allergic responses, and increased eosinophilic inflammation and mast cell mediator release $[10,11]$. In health administrative database studies, patients with a lower ratio of ICS to SABA were at greater risk of hospitalisation and urgent admission [12], whereas population-based strategies that increased access to ICS were associated with reduced hospitalisations and deaths $[13,14]$. However, adherence with ICS is poor in real life, often only $25-35 \%$ of the prescribed dose [15], leaving patients exposed to the risks of SABA-only treatment [16]. Multiple factors contribute to poor adherence [17], including lack of perceived necessity (especially if symptoms are few [18]), perceived and actual side-effects, and cost; few interventions have been effective in improving adherence.

Of particular concern to GINA was the paradoxical switch in messaging for patients and clinicians between Step 1, where symptom relief was the priority and SABA use was encouraged, and Step 2, where patients were told that they should reduce what was to them a familiar, effective, low cost treatment, and that to achieve this, they should take a daily treatment even when asymptomatic $[19,20]$. Patient reliance on SABA was further reinforced by its prominent use in the trusted environments of emergency department and hospital care.

\section{BOX 1 What is GINA?}

The Global Initiative for Asthma (GINA) was established by the World Health Organization and the National Heart Lung and Blood Institute in 1993, to increase awareness about asthma among health professionals, public health authorities and the community, and to improve asthma prevention and management through a coordinated worldwide effort. GINA prepares scientific reports on asthma, encourages dissemination and implementation of the recommendations, and promotes international collaboration on asthma research. GINA does not accept donations. The work of GINA is supported only by the sale and licensing of GINA reports and its other publications, and by the voluntary work of GINA committee members.

The GINA report, which is updated annually, comprises an integrated strategy focusing not only on evidence, but also on translation into clinical practice. Evidence is considered and recommendations are framed, not as discrete questions, but in the context of their relationship to the overall goals of treatment, underlying disease processes, feasibility for implementation in clinical practice, evidence about human behaviour (of health professionals and of patients/carers), and variation in populations, health systems and medication access in different countries. The GINA strategy has a strong focus on preventing asthma-related deaths and severe exacerbations, as well as on efficacy and effectiveness for symptom control and lung function, and it promotes personalised treatment decisions across the spectrum of asthma severity.

The GINA 2019 report and other GINA publications can be purchased, or downloaded free for personal use, from the GINA website (www.ginasthma.org). A description of GINA methodology is also available on the GINA website. 
From 2007, based on evidence that exacerbations were significantly reduced by low dose ICS-formoterol maintenance and reliever therapy in moderate-severe asthma [21] and, in a study by PAPI et al. [22], by as-needed beclometasone dipropionate (BDP)-salbutamol in patients stepping down from moderate dose ICS, GINA members repeatedly submitted proposals for studies of as-needed controller in mild asthma. For this purpose, the combination of ICS-formoterol was preferred over ICS-SABA as it was more widely available, and because of adverse outcomes with regular use of ICS-SABA in the study by PAPI et al. [22]. The aim of the GINA proposals was to improve management of mild asthma by a strategy that would reduce the risk of severe exacerbations while also being concordant with patient behaviour, beliefs and preferences.

The need for such studies was supported by the findings of the UK National Review of Asthma Deaths in 2014, that $9 \%$ of asthma deaths were in patients being treated with SABA alone (suggesting that their physician had considered they had mild asthma), and 39\% were associated with excess prescriptions for SABA [23]. In 2014, GINA recommended that SABA-only treatment should be restricted to patients with symptoms twice a month or less and with no risk factors for exacerbations. However, it was recognised that this cut-off was arbitrary, and that patients with infrequent symptoms would be unlikely to be adherent with daily ICS, reverting to SABA-only treatment. In addition, there was a paucity of evidence for feasible alternatives. The first studies that were able to fill this gap were the large SYGMA studies of as-needed budesonide-formoterol in mild asthma, published in 2018 [24, 25].

In 2019, GINA undertook a comprehensive review of evidence on the adverse outcomes of SABA-only treatment and the impact on asthma exacerbations and deaths of any form of ICS in mild asthma, and resolved that there was now sufficient evidence to recommend that adults and adolescents with asthma should not be treated with SABA alone. Instead, they should receive either symptom-driven (in mild asthma) or daily ICS-containing treatment, to reduce their risk of serious exacerbations. Several treatment options for achieving this are recommended in the GINA 2019 strategy report (figure 1).

For Step 2 (for patients with symptoms twice a month or more, or with risk factors for exacerbations), the previous recommendation for daily low dose ICS remains. In making this recommendation, high importance was given to the weight of evidence that ICS reduces asthma-related deaths [6], and that it reduces exacerbations even in so-called "intermittent" asthma [26]. However, before choosing this option, the clinician should consider whether a patient is likely to be adherent with daily ICS, or default to SABA-only treatment with its attendant risks. The other "preferred controller option" for Step 2 is as-needed low dose ICS-formoterol. Here, high importance was given to the almost two-thirds reduction in severe exacerbations seen with this treatment when compared with SABA alone [25], and non-inferiority to daily ICS for severe exacerbations in SYGMA 1 and 2, achieved without the need for daily treatment and at a considerably lower dose of ICS (a quarter or less) [24, 25]. Lower importance was given to small non-cumulative differences seen in the SYGMA studies $[24,25]$ for forced expiratory volume in $1 \mathrm{~s}(\sim 30-$ $50 \mathrm{~mL}$ ), symptom control (difference in Asthma Control Questionnaire (ACQ-5) 0.15 versus the minimal clinically important difference of 0.5 ), and symptom-free days (mean difference 10.6 days per year) compared with regular ICS. When ICS-formoterol was used as-needed and pre-exercise, protection against exercise-induced bronchoconstriction was obtained, of similar magnitude to that obtained with regular ICS plus as-needed and pre-exercise SABA [27]. Evidence to date for as-needed ICS-formoterol is based on studies with low dose combination budesonide-formoterol, but low dose BDP-formoterol could potentially be used in the same way, given its efficacy in maintenance and reliever therapy [28].

GINA also provides additional as-needed controller options for Step 2 strategies that may reduce exacerbations, albeit with limited evidence. The option of taking ICS whenever SABA is taken is based on one study with as-needed combination BDP-salbutamol [22], and two studies (one in 5-18 year olds [29] and one in adults [30]) with separate ICS and salbutamol inhalers, in which exacerbations were reduced compared with SABA alone and reduced or the same compared with regular ICS, at an average of $\sim 15-$ $25 \%$ of the ICS dose. Leukotriene receptor antagonists are still included as a Step 2 option, but they are not preferred as they are less effective than daily ICS for preventing exacerbations and do not avoid the need for a reliever [31].

Step 1 is for patients with symptoms less than twice a month. Here, no direct evidence is available, but the rationale for the "preferred" controller option of as-needed ICS-formoterol, or for taking ICS whenever $\mathrm{SABA}$ is taken, is based on indirect evidence from the corresponding Step 2 studies. In formulating the Step 1 recommendations, high importance was given to prevention of severe exacerbations, and to avoidance of contradictions in asthma messaging between Step 1 and Step 2. Regular ICS is not recommended for Step 1, because it was considered extremely unlikely that patients with such infrequent symptoms would be prepared to take a daily treatment.

Currently, all of these as-needed strategies are technically "off-label", as ICS, ICS-formoterol and ICSSABA are indicated only for regular use in most countries. However, the safety of ICS-formoterol has 


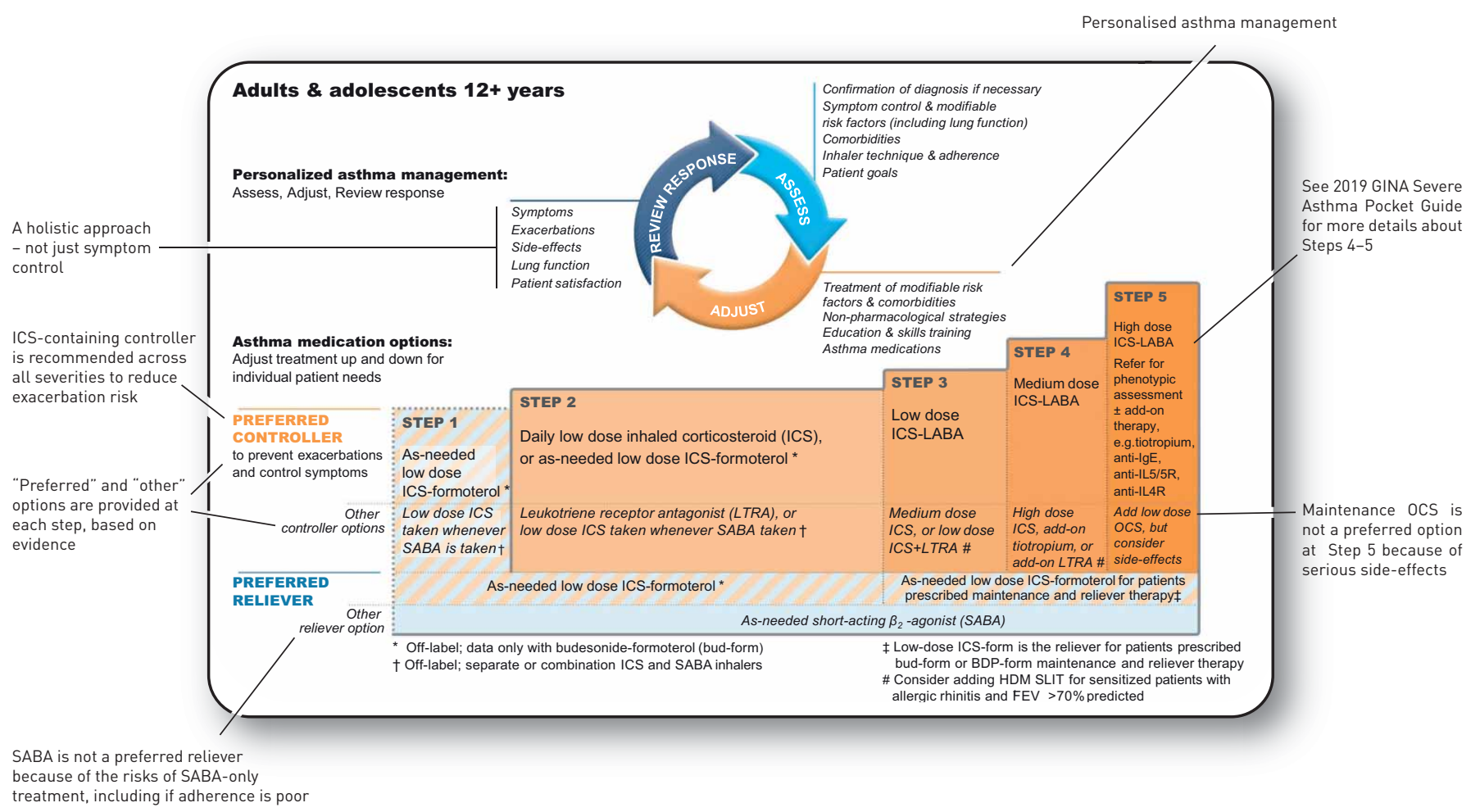

FIGURE 1 The 2019 Global Initiative for Asthma (GINA) treatment strategy figure for adults and adolescents, annotated to highlight key features. ICS: inhaled corticosteroids; SABA: short-acting $\beta_{2}$-agonists; LTRA: leukotriene receptor antagonists; LABA: long-acting $\beta_{2}$-agonists; OCS: oral corticosteroids; BDP: beclometasone dipropionate; HDM: house dust mite; SLIT: sublingual immunotherapy; FEV1: forced expiratory volume in 1 s; IL: interleukin. Modified with permission of the Global Initiative for Asthma (www.ginasthma.org).

been established over many years, including with maintenance and reliever therapy [32], and no new safety signals emerged in the recent large studies $[24,25]$. Combination ICS-SABAs are available in a few countries, but with limited safety data.

The changes recommended in GINA 2019 represent a major reorientation in how we treat the largest group of asthma patients. In recommending these changes, GINA recognises that there are questions to be addressed, including the cost of implementation in low and high income countries; pharmacoeconomic analyses are underway. Exacerbations are infrequent events in mild asthma; in the closely monitored SYGMA 1 study, only $12 \%$ of patients receiving as-needed SABA experienced a severe exacerbation in 12 months [25]. However, unusually among chronic diseases, patients with apparently mild asthma are over-represented in serious outcomes: $30-37 \%$ of adults with acute asthma, $16 \%$ of patients with near-fatal asthma, and $15-20 \%$ of adults dying of asthma had asthma symptoms less than weekly in the previous 3 months [33]. Controller treatment for mild asthma represents a population-level risk reduction strategy, similar to treatment of hypertension or hypercholesterolaemia, where one cannot know whether any individual patient has avoided a serious outcome. Large long-term studies would be needed to identify patients for whom it would be safe (in terms of risk of severe exacerbations or death) to treat without any ICS. There is no contradiction in employing a background population-level risk reduction strategy as part of personalised asthma management, as shown in figure 1.

Additional studies, already underway, will provide further evidence about the utility and implementation of these strategies in clinical practice. These include two open-label randomised controlled trials, representing the way that patients would use as-needed ICS-formoterol in real life [34, 35]; both of these studies include type 2 biomarkers at baseline and during treatment. Qualitative research has been conducted to provide the patient perspective on treatment regimens in mild asthma.

Studies of as-needed ICS-formoterol are still needed in children, where reliance on SABA is currently established and maintained. There is only one study to date of as-needed ICS-SABA in children [29], and none with as-needed ICS-formoterol. Other populations in whom as-needed ICS-formoterol should be investigated include pregnant women, where protection from exacerbations with a very low dose of ICS may be particularly attractive, and patients with seasonal allergic asthma. Studies of airway hyperresponsiveness, and of the relationship between symptoms, lung function and use of ICS-formoterol 
reliever are needed, in order to understand the mechanism by which exacerbations are reduced. Head-to-head studies of as-needed ICS-formoterol and ICS-SABA are needed, to compare efficacy and safety.

As a global initiative, GINA aims to improve asthma care by presenting evidence-based treatment options. Explicitly, it recognises that each country and jurisdiction must determine at a local level the options best suited to their resources and needs. Although the public health implications of these major changes in GINA recommendations remain to be studied, their potential is great, both in economically developed countries and in low income countries where access to ICS-containing medications, particularly as maintenance therapy, is limited or non-existent. Although budesonide-formoterol is now included in the World Health Organization list of essential medicines, it is not currently available or affordable in many countries, but changes in treatment policies provide the opportunity for motivating greater access to this simplified form of care. These are also the countries in which the burden of potentially preventable asthma hospitalisations and deaths are greatest and in which the cost-effectiveness of the new approach might be best seen. Regular ICS maintenance treatment has been around for more than 40 years. Even in resource-rich countries, despite the best efforts of health professionals, adherence to maintenance treatment with ICS in mild asthma remains a distant hope. 2019 may represent the start of a new chapter for patients with mild asthma.

Acknowledgements: The authors acknowledge with respect and gratitude the tireless work of Claude Lenfant and Suzanne Hurd for GINA, from its establishment in 1993 until their retirement in 2014, and of Rebecca Decker, the Global Program Director for GINA, since 2014.

The authors are members of the GINA Science Committee and/or the GINA Board. Louis-Philippe Boulet is Chair of the GINA Board; Helen K. Reddel is Chair of the GINA Science Committee; and Mark L. Levy is Chair of the GINA Dissemination and Implementation Committee.

Conflict of interest: H.K. Reddel reports grants and personal fees for data monitoring committee and advisory board work, and providing independent medical education and consultancy from AstraZeneca, grants, personal fees for data monitoring committee and advisory board work, and providing independent medical education and consultancy, and non-financial support (study medication) from GlaxoSmithKline, personal fees for data monitoring committee work from Merck, grants and personal fees for data monitoring committee and advisory board work, and providing independent medical education from Novartis, personal fees for providing independent medical education from Teva and Mundipharma, personal fees for advisory board work and providing independent medical education from Boehringer Ingelheim, outside the submitted work; and H.K Reddel is Chair of the GINA Scientific Committee. J.M. FitzGerald reports grants and personal fees for advisory board work and speaker bureau-related presentations from AstraZeneca, GSK and Sanofi Regeneron, grants from Novartis, Boehringer Ingelheim and TEVA, during the conduct of the study; and is a member of the Executive and Science Committees of GINA. E.D. Bateman is a member of the Science Committee and Board of GINA; reports personal fees from ALK, AstraZeneca, Boehringer Ingelheim, Cipla, Menarini, Novartis, Orion, Regeneron, Sanofi Genzyme and Vectura, and grants to his institution from AstraZeneca, Boehringer Ingelheim, GlaxoSmithKline, Novartis, Sanofi-Aventis and TEVA, outside the submitted work. L.B. Bacharier reports personal fees for lecturing and consultancy from Aerocrine, GlaxoSmithKline, Genentech/Novartis, Teva, Boehringer Ingelheim and AstraZeneca, personal fees for advisory board work from Merck and Circassia, personal fees for data monitoring committee work from DBV Technologies, personal fees for CME programme development from WebMD/Medscape, personal fees for lecturing and advisory board work from Sanofi/Regeneron, personal fees for consultancy and advisory board work from Vectura, outside the submitted work. A. Becker reports personal fees for continuing medical education from AstraZeneca, personal fees for lecturing from Johnson and Johnson, and MSD, personal fees for advisory board work from Novartis, outside the submitted work. G. Brusselle reports personal fees for lecturing and advisory board work from AstraZeneca, Boehringer Ingelheim, Chiesi, GlaxoSmithKline, Novartis and Teva, personal fees for advisory board work from Sanofi, outside the submitted work. R. Buhl reports personal fees from AstraZeneca, Boehringer Ingelheim, Chiesi, Cipla, Novartis, Roche, and Teva, outside the submitted work, as well as grants to Mainz University from Boehringer Ingelheim, GlaxoSmithKline, Novartis, and Roche, also outside the submitted work. A.A. Cruz reports grants and personal fees for advisory board work from GSK, grants, personal fees for lecturing and advisory board work and non-financial support for meeting attendance from AstraZeneca, personal fees for lecturing, developing educational materials and advisory board work, and non-financial support for meeting attendance from Boehringer Ingelheim, personal fees for lecturing and non-financial support for meeting attendance from Chiesi, personal fees for lecturing and developing educational materials, and non-financial support for meeting attendance from EUROFARMA and MEDA Pharma, personal fees for lecturing from Novartis, personal fees for consultancy and advisory board work from Sanofi, outside the submitted work. L. Fleming reports grants from Asthma UK, and speaker and consutancy fees, all paid direct to her institution, from Boehringer Ingelheim, AstraZeneca, GSK, Sanofi, Respiri and Novartis, outside the submitted work. H. Inoue reports grants from Boehringer Ingelheim, Kyorin, MeijiSeikaPharma, Novartis, Ono, Taiho and Teijin-Pharma, personal fees for lecturing and advisory board work from Astellas, AstraZeneca, Boehringer Ingelheim, GlaxoSmithKline, Kyorin, Merck Sharp \& Dohme, Novartis, Otsuka and Sanofi, outside the submitted work. F.W. Ko has nothing to disclose. J.A. Krishnan reports research grants from the US National Institutes of Health (current), research contracts from the US Patient Centered Outcomes Research Institute (current), and personal fees from Sanofi to serve on an independent data monitoring committee, outside the submitted work. M.L. Levy reports personal fees for consultancy from Clement Clarke International, personal fees for lecturing from Teva and Soar Beyond, personal fees for advisory board work from AstraZeneca, Orion Pharmaceuticals, GlaxoSmithKline and Trudel Pharmaceuticals, non-financial (travel) support from and is a board member of GINA, personal fees for data monitoring committee work and travel support from Chiesi, grants from Conzorcio Futuro In 
Ricerca, support for meeting attendance from Napp Pharmaceuticals, personal fees for consultancy from National Services for Health Improvement, a company providing services for practices (Nurse asthma reviews), personal fees for lecturing and advisory board work from Novartis Pharmaceuticals, and support from Whole Systems Integrated Care (WSIC) for whom M.L. Levy is lead on asthma and joint lead for COPD in developing dashboards for clinical care for general practitioners in London, outside the submitted work. J. Lin has nothing to disclose. S.E. Pedersen reports personal fees for lectures and consultancy from Astrazeneca, personal fees for consultancy from ALK and Thermofisher, outside the submitted work. A. Sheikh reports support for meeting attendance from GSK, grants from Asthma UK, and other support from the Scottish Allergy and Respiratory Academy (a not-for-profit training initiative for health care professionals supported by a consortium of industry funders), outside the submitted work. A. Yorgancioglu reports grants from MSD, personal fees for advisory board work from GSK, personal fees for advisory board work and lecturing from AstraZeneca, Abdi İbrahim, Chiesi, Novartis and Sandoz, outside the submitted work. L-P. Boulet reports research grants for participation in multicentre studies from AstraZeneca, Boston Scientific, GlaxoSmithKline, Hoffman La Roche, Novartis, Ono Pharma, Sanofi and Takeda; support for research projects from AstraZeneca, Boehringer Ingelheim, GlaxoSmithKline, Merck and Takeda; fees for consulting and advisory board work from AstraZeneca, Novartis and Methapharm; royalties as co-author of "Up-To-Date" (occupational asthma); nonprofit grants for production of educational materials from AstraZeneca, Boehringer Ingelheim, GlaxoSmithKline, Merck, Frosst and Novartis; conference fees from AstraZeneca, GlaxoSmithKline, Merck and Novartis; support for participation in conferences and meetings from Novartis and Takeda; is past president and member of the Canadian Thoracic Society Respiratory Guidelines Committee; Chair of the Board of Directors of the Global Initiative for Asthma (GINA); Laval University Chair on Knowledge Transfer, Prevention and Education in Respiratory and Cardiovascular Health; member of scientific committees for the American College of Chest Physicians, American Thoracic Society, European Respiratory Society and the World Allergy Organization; 1st Vice-President of the Global Asthma Organization "InterAsma".

\section{References}

1 Crompton G. A brief history of inhaled asthma therapy over the last fifty years. Prim Care Respir J 2006; 15: 326-331.

2 Suissa S, Ernst P, Boivin JF, et al. A cohort analysis of excess mortality in asthma and the use of inhaled beta-agonists. Am J Respir Crit Care Med 1994; 149: 604-610.

3 Abramson MJ, Bailey MJ, Couper FJ, et al. Are asthma medications and management related to deaths from asthma? Am J Respir Crit Care Med 2001; 163: 12-18.

4 Drazen JM, Israel E, Boushey HA, et al. Comparison of regularly scheduled with as-needed use of albuterol in mild asthma. Asthma Clinical Research Network. N Engl J Med 1996; 335: 841-847.

5 Dennis SM, Sharp SJ, Vickers MR, et al. Regular inhaled salbutamol and asthma control: the TRUST randomised trial. Therapy Working Group of the National Asthma Task Force and the MRC General Practice Research Framework. Lancet 2000; 355: 1675-1679.

6 Suissa S, Ernst P, Benayoun S, et al. Low-dose inhaled corticosteroids and the prevention of death from asthma. N Engl J Med 2000; 343: 332-336.

7 Suissa S, Ernst P, Kezouh A. Regular use of inhaled corticosteroids and the long term prevention of hospitalisation for asthma. Thorax 2002; 57: 880-884.

8 O’Byrne PM, Barnes PJ, Rodriguez-Roisin R, et al. Low dose inhaled budesonide and formoterol in mild persistent asthma: the OPTIMA randomized trial. Am J Respir Crit Care Med 2001; 164: 1392-1397.

9 Pauwels RA, Pedersen S, Busse WW, et al. Early intervention with budesonide in mild persistent asthma: a randomised, double-blind trial. Lancet 2003; 361: 1071-1076.

10 Taylor DR, Sears MR, Cockcroft DW. The beta-agonist controversy. Med Clin North Am 1996; 80: 719-748.

11 Hancox RJ. Concluding remarks: can we explain the association of beta-agonists with asthma mortality? A hypothesis. Clin Rev Allergy Immunol 2006; 31: 279-288.

12 Anis AH, Lynd LD, Wang XH, et al. Double trouble: impact of inappropriate use of asthma medication on the use of health care resources. CMAJ 2001; 164: 625-631.

13 Haahtela T, Tuomisto LE, Pietinalho A, et al. A 10 year asthma programme in Finland: major change for the better. Thorax 2006; 61: 663-670.

14 Souza-Machado C, Souza-Machado A, Franco R, et al. Rapid reduction in hospitalisations after an intervention to manage severe asthma. Eur Respir J 2010; 35: 515-521.

15 Boulet L-P, Vervloet D, Magar Y, et al. Adherence: the goal to control asthma. Clin Chest Med 2012; 33: 405-417.

16 Williams LK, Peterson EL, Wells K, et al. Quantifying the proportion of severe asthma exacerbations attributable to inhaled corticosteroid nonadherence. J Allergy Clin Immunol 2011; 128: 1185-1191.

17 Horne R. Compliance, adherence, and concordance: implications for asthma treatment. Chest 2006; 130: 65S-72S.

18 Barnes CB, Ulrik CS. Asthma and adherence to inhaled corticosteroids: current status and future perspectives. Respir Care 2015; 60: 455-468.

19 O’Byrne PM, Jenkins C, Bateman ED. The paradoxes of asthma management: time for a new approach? Eur Respir J 2017; 50: 1701103.

20 Beasley R, Bird G, Harper J, et al. The further paradoxes of asthma management: time for a new approach across the spectrum of asthma severity. Eur Respir J 2018; 52: 1800694.

21 Cates CJ, Lasserson TJ. Combination formoterol and budesonide as maintenance and reliever therapy versus inhaled steroid maintenance for chronic asthma in adults and children. Cochrane Database Syst Rev 2009: CD007313.

22 Papi A, Canonica GW, Maestrelli P, et al. Rescue use of beclomethasone and albuterol in a single inhaler for mild asthma. N Engl J Med 2007; 356: 2040-2052.

23 Royal College of Physicians. Why Asthma Still Kills: The National Review of Asthma Deaths (NRAD) Confidential Enquiry Report. 2014. www.rcplondon.ac.uk/file/868/download?token=3wikiuFg Last accessed: May 2019.

24 Bateman ED, Reddel HK, O’Byrne PM, et al. As-needed budesonide-formoterol versus maintenance budesonide in mild asthma. N Engl J Med 2018; 378: 1877-1887.

25 O’Byrne PM, FitzGerald JM, Bateman ED, et al. Inhaled combined budesonide-formoterol as needed in mild asthma. N Engl J Med 2018; 378: 1865-1876. 
Reddel HK, Busse WW, Pedersen S, et al. Should recommendations about starting inhaled corticosteroid treatment for mild asthma be based on symptom frequency: a post-hoc efficacy analysis of the START study. Lancet 2017; 389: 157-166.

27 Lazarinis N, Jørgensen L, Ekström T, et al. Combination of budesonide/formoterol on demand improves asthma control by reducing exercise-induced bronchoconstriction. Thorax 2014; 69: 130-136.

28 Papi A, Corradi M, Pigeon-Francisco C, et al. Beclometasone-formoterol as maintenance and reliever treatment in patients with asthma: a double-blind, randomised controlled trial. Lancet Respir Med 2013; 1: 23-31.

29 Martinez FD, Chinchilli VM, Morgan WJ, et al. Use of beclomethasone dipropionate as rescue treatment for children with mild persistent asthma (TREXA): a randomised, double-blind, placebo-controlled trial. Lancet 2011; 377: 650-657.

30 Calhoun WJ, Ameredes BT, King TS, et al. Comparison of physician-, biomarker-, and symptom-based strategies for adjustment of inhaled corticosteroid therapy in adults with asthma: the BASALT randomized controlled trial. JAMA 2012; 308: 987-997.

31 Chauhan BF, Ducharme FM. Anti-leukotriene agents compared to inhaled corticosteroids in the management of recurrent and/or chronic asthma in adults and children. Cochrane Database Syst Rev 2012; 5: CD002314.

32 Sobieraj DM, Weeda ER, Nguyen E, et al. Association of inhaled corticosteroids and long-acting beta-agonists as controller and quick relief therapy with exacerbations and symptom control in persistent asthma: A systematic review and meta-analysis. JAMA 2018; 319: 1485-1496.

33 Dusser D, Montani D, Chanez P, et al. Mild asthma: an expert review on epidemiology, clinical characteristics and treatment recommendations. Allergy 2007; 62: 591-604.

34 Beasley R, Holliday M, Reddel HK, et al. Controlled trial of budesonide-formoterol as needed for mild asthma. N Engl J Med 2019; 380: 2020-2030.

35 Fingleton J, Hardy J, Baggott C, et al. Description of the protocol for the PRACTICAL study: a randomised controlled trial of the efficacy and safety of ICS/LABA reliever therapy in asthma. BMJ Open Respir Res 2017; 4: e000217. 